\title{
COCRIAÇÃO NA INTERNET: UMA ANÁLISE DAS PERSPECTIVAS DA EMPRESA E DO CONSUMIDOR
}

\author{
Melby Karina Zuniga Huertas \\ Doutorado em Administração pela Universidade de São Paulo - USP \\ Professora do Programa de Mestrado e Doutorado do Centro Universitário da FEI - FEI \\ mhuertas@fei.edu.br
}

\section{Carmen Augusta Varela}

Doutora em Economia de Empresas pela Fundação Getúlio Vargas - FGV/ EAESP

Professora do Programa de Mestrado e Doutorado em Administração do Centro Universitário da FEISP

cvarela@fei.edu.br

\section{Suzane Strehlau}

Doutora em Economia de Empresas pela Fundação Getúlio Vargas - FGV/ EAESP

Professora do Programa Mestrado e Doutorado em Administração da Universidade Nove de Julho PPGA/UNINOVE

suzanes@uninove.br

\section{RESUMO}

O objetivo da pesquisa foi estudar cocriação na internet no Brasil a partir de duas perspectivas: a da empresa, com a identificação das ferramentas disponibilizadas para propiciar a participação do consumidor em processos de cocriação; a do consumidor, com a análise dos papéis desempenhados por ele nesse processo. O método de pesquisa foi a Análise de Conteúdo de websites e de participações dos consumidores. Os resultados mostram uso restrito das ferramentas e papel do consumidor apenas como usuário. As descobertas podem auxiliar as empresas a viabilizar a participação do consumidor ao longo das diversas etapas do processo de desenvolvimento de produtos e serviços. Outras implicações estão na produção de insights para maior efetividade na utilização da internet, visando à criação de valor para o consumidor.

Palavras-chave: Cocriação; Internet; Consumidor; Novos Produtos; Telefonia Celular. 


\section{INTRODUÇÃO}

$\mathrm{Na}$ visão de marketing, para que um novo produto seja introduzido no mercado e comercializado com sucesso, ele deve gerar valor para o consumidor (Urdan \& Urdan, 2006). Ou seja, quem consome ou usa a nova oferta deve perceber nela mais benefícios do que custos. Esse seria o grande desafio quando se trata de inovação em produtos: gerar valor para o consumidor. O sucesso em novos produtos é recompensador e necessário para manter uma organização saudável. Porém, a introdução de novos produtos pode ser arriscada, e chamam a atenção as altas taxas de fracasso e os custos pesados correspondentes. Atualmente, de 33\% a mais de $60 \%$ dos lançamentos fracassam (Srinivasan et al., 2009). Isso mostra a importância estratégica de incorporar as competências do consumidor no processo de desenvolvimento de novos produtos (Vargo \& Lusch, 2004), pois seria possível diminuir essas taxas. Logo, a cocriação, convertendo o consumidor em uma nova fonte de competência para a organização, é essencial (Prahalad \& Ramaswamy, 2000).

A tecnologia da informação e a internet, em particular, estão constantemente mudando a dinâmica do mercado. Nessa realidade, a proliferação de novas tecnologias nas interações consumidorempresa tem refinado o papel dos consumidores nos processos de inovação e criação de valor (Thomke \& Von Hippel, 2002). Assim, o desafio de lançar produtos que de fato gerem valor para o consumidor estaria se tornando mais viável com o uso da internet. Nesse cenário surgem algumas questões que reclamam evidência empírica: como as empresas propiciam a participação do consumidor na internet nos seus processos de desenvolvimento de novos produtos? Como os consumidores utilizam as ferramentas disponibilizadas na internet pelas empresas, para participar no desenvolvimento de novos produtos? Orientado por essas questões ainda sem respostas no ambiente acadêmico no Brasil, surge o objetivo geral desta pesquisa: estudar cocriação na internet no mercado brasileiro.

\section{COCRIAÇÃO NA INTERNET}

Nos últimos anos, uma ênfase da pesquisa acadêmica na área de marketing tem sido no papel do consumidor como cocriador de valor (Vargo \& Lush, 2004; Grönroos, 2006). A ideia de cocriação de valor envolve a interação entre consumidores/clientes (pessoas e organizações, respectivamente) e empresas com acesso bilateral de informações, em que a experiência individual de cada consumidor/cliente, em um determinado tempo e momento, resulta na criação e definição do valor a 
ser agregado ao bem/serviço (Prahalad \& Ramaswany, 2004). O interesse deste trabalho é na interação consumidor-empresa.

Numa grande variedade de setores, a integração do consumidor melhora o desempenho do processo de desenvolvimento de produtos, que torna o tempo, entre a geração da ideia e o lançamento do produto, mais curto e os produtos desenvolvidos mais ajustados às necessidades do mercado (Prandelli et al., 2006). Todavia, argumenta-se que as empresas que tenham habilidade para identificar as necessidades do consumidor e alinhá-las às suas competências serão as campeãs da inovação (Matzler \& Bailom, 2006). A habilidade de envolver o consumidor na criação de novos produtos, embora não seja uma tarefa fácil, é altamente recomendada na teoria e na prática (Prandelli et al., 2006).

\begin{tabular}{|l|ll|}
\hline Estágio do Processo de Inovação & \multicolumn{2}{c|}{ Ferramentas } \\
\hline Geração de Ideias & 1. & Opção de contato com a empresa \\
& 2. & Levantamento de feedback \\
& 3. & Caixa de sugestões \\
& 4. & Área de reclamações \\
& 5. & Comunidade virtual \\
& 6. & Mecanismos formais de competição de novas ideias \\
& 7. & Área de acordos sobre a propriedade intelectual das ideias \\
& 8. & Programas de cliente consultor \\
& 9. & Fóruns de discussão \\
& 10. & Centros de conhecimento \\
& 11. & Blogs \\
\hline Seleção de Ideias & 12. & Wikis \\
\hline Design de Produto & 13. & Análise de opiniões do consumidor \\
& 14. & Teste virtual de conceitos \\
& 15. & Grupo de foco online \\
\hline Lançamento & 16. & Customização em massa de atributos estéticos \\
& 17. & Customização em massa de atributos funcionais \\
& 18. & Patentes de usuários para novos produtos \\
& 19. & Mecanismos abertos \\
& 20. & Ferramentas de design \\
& 21. & Equipes virtuais \\
& 22. & Ferramentas virtuais de design e prototipagem \\
& 23. & Ferramentas de mensagens \\
\hline Teste de Produto & 24. & Teste virtual de produto \\
& 25. & Teste de mercado \\
& 26. & Ferramentas virtuais de simulação de produtos \\
& 27. & Ferramentas de mensagens \\
\hline & 28. & Área do novo produto \\
& 29. & Eventos \\
& 30. & Notícias personalizadas \\
& 31. & Comunidades virtuais \\
& 32. & Marketing viral \\
& 33. & Assistência personalizada para seleção do produto \\
\hline & & \\
& &
\end{tabular}

Revista de Administração e Inovação, São Paulo, v. 9, n.3, p. 257-272, jul/set. 2012. 


\begin{tabular}{|l|ll|}
\hline & 34. & Mini websites \\
& 35. & Fóruns de discussão \\
\hline Gerenciamento do Ciclo de & 36. & Centros de conhecimento \\
Vida do Produto & 37. & Gestão personalizada do relacionamento \\
& 38. & Notícias personalizadas \\
& 39. & Fóruns de discussão \\
& 40. & Ferramentas virtuais de simulação do produto \\
\hline
\end{tabular}

Figura 1 - Ferramentas de Cocriação na Internet nos Estágios do Processo de Desenvolvimento de Produtos

Fonte: Elaborado a partir de Prandelli et al., 2006, p. 116, e Nambisan \& Nambisan, 2008, p. 55

Desde a última década do século passado, a participação do consumidor contribuiria com o processo de desenvolvimento de produtos e a criação de valor de forma efetiva (Brown \& Eisenhardt, 1995). Contudo, na prática, o envolvimento do consumidor era limitado e passivo nesse processo, na maioria dos setores (Wayland \& Cole, 1997). Várias podem ter sido as razões para essa situação indesejável, mas o fator mais limitante seria a pobreza da conectividade entre o consumidor e a empresa no passado (Nambisan, 2002). Com o avanço tecnológico e a internet, é possível que esse fator limitador esteja sendo superado.

A internet permite ao consumidor expressar suas opiniões e criatividade numa escala sem precedentes (Palmer, 2007). Isso teria produzido formas radicalmente novas de as empresas codesenvolver produtos, soluções e estratégias com os consumidores. Surgiram assim os Ambientes Virtuais do Consumidor (AVC) que abrangem desde simples fóruns de discussão online até os mais sofisticados centros de protótipos de produtos (Nambisan, 2002).

Nessa realidade, o desafio para os gerentes é desenvolver formas de compreender cada vez melhor a natureza das experiências dos consumidores nos AVC e as suas implicações para a inovação e a gestão do relacionamento (Nambisan \& Nambisan, 2008).

Na literatura sobre cocriação, há indícios de que as empresas estão fazendo uso de várias formas de AVC, mostrando que o consumidor já está sendo incorporado no processo de desenvolvimento de produtos (Nambisan \& Nambisan, 2008). Essas várias formas de AVC, que daqui em diante denominamos ferramentas de cocriação na internet, têm sido desenvolvidas para alavancar a colaboração dos consumidores em cada estágio do processo de desenvolvimento de produtos (Prandelli et al., 2006). A Figura 1 mostra ferramentas de cocriação na internet utilizadas em cada estágio desse processo. As ferramentas sombreadas são as sugeridas por Nambisan \& Nambisan (2008), as outras por Prandelli et al. (2006). Por restrições de espaço, aqui não é feita a descrição de cada ferramenta, mas esclarecimentos sobre algumas delas são feitos ao longo do artigo. Pelas características da internet entende-se que essas ferramentas não sejam estáticas nem exaustivas, mudando constantemente. Todavia, podem servir como ponto de partida para pesquisas em outras empresas e outros contextos.

Revista de Administração e Inovação, São Paulo, v. 9, n.3, p. 257-272, jul/set. 2012. 
Como no Brasil pouco se sabe sobre a utilização da internet para cocriação, surge o primeiro objetivo específico desta pesquisa: identificar as ferramentas disponibilizadas pelas empresas na internet para propiciar a participação do consumidor no processo de cocriação de valor.

\subsection{O papel do consumidor no desenvolvimento de produtos}

Tradicionalmente, em desenvolvimento de produtos, a fonte de informações para engenheiros, designers e profissionais de marketing das empresas era a pesquisa com consumidores, focada em revelar necessidades não reconhecidas (Palmer, 2007). Nessa abordagem, que é chamada aqui de tradicional, a participação do consumidor no processo seria por meio de grupos de foco, levantamentos e outras técnicas de pesquisa tipicamente usadas para validar conceitos de produto gerados dentro da empresa e não para gerar novas ideias.

Em uma abordagem mais moderna, a participação do consumidor no processo de desenvolvimento de produtos é sintetizada em três papéis fundamentais (Nambisan, 2002). A Figura 2 mostra um resumo desses papéis do cliente (abrangendo o consumidor industrial e o consumidor individual) em quatro fases desse processo, além de algumas questões-chave e os respectivos desafios gerenciais.

\begin{tabular}{|c|c|c|}
\hline Papel do Cliente & Fase do PDP & Questões-Chave/Desafios Gerenciais \\
\hline Recurso & Ideação & $\begin{array}{l}\text { - Apropriação do cliente como fonte de inovação } \\
\text { - Seleção do cliente inovador } \\
\text { - Necessidade de variedade de incentivos para o } \\
\text { cliente } \\
\text { - Estrutura para capturar conhecimento do cliente } \\
\text { - Diferentes papéis dos clientes reais e potenciais }\end{array}$ \\
\hline Cocriador & $\begin{array}{c}\text { Design e } \\
\text { desenvolvimento }\end{array}$ & $\begin{array}{l}\text { - Envolvimento em uma ampla gama de tarefas de } \\
\text { design e desenvolvimento } \\
\text { - Natureza do contexto de desenvolvimento de } \\
\text { produtos: industrial/consumidor } \\
\text { - Maior entrosamento com as equipes internas de } \\
\text { desenvolvimento } \\
\text { - Gerenciar a incerteza de participação no projeto } \\
\text { - Reforçar o conhecimento dos clientes sobre o } \\
\text { produto ou tecnologia }\end{array}$ \\
\hline \multirow[t]{2}{*}{ Usuário } & Teste de produto & $\begin{array}{l}\text { - Atividade de tempo muito limitado } \\
\text { - Garantir a diversidade de clientes }\end{array}$ \\
\hline & $\begin{array}{l}\text { Suporte de } \\
\text { produto }\end{array}$ & $\begin{array}{l}\text { - Atividade sempre em andamento } \\
\text { - Estrutura para interações cliente-cliente }\end{array}$ \\
\hline
\end{tabular}

Figura 2 - Papéis do Cliente no Processo de Desenvolvimento de Produtos (PDP)

Fonte: Nambisan, 2002, p. 395 
Na ideação, o cliente é considerado um Recurso. Ele é uma fonte de ideias, e a empresa deve estar preparada para selecionar clientes inovadores, capturar seu conhecimento e oferecer incentivos adequados. Na fase de design e desenvolvimento, o cliente passa a ser Cocriador, sendo envolvido numa série de atividades como a validação e escolha do escopo do produto, suas características e especificações. A empresa deve propiciar a aceitação (entrosamento) e o engajamento do cliente (gerenciar desistências) com a equipe de desenvolvimento, além de reforçar o conhecimento sobre a tecnologia do produto em discussão. Para que o cliente possa incorporar sua função de cocriador, ele precisará ter acesso a um nível alto de conhecimento da tecnologia e do produto envolvido. Por fim, na etapa de teste e suporte do produto, o cliente passa a ser um Usuário. A fase de teste do produto junto ao cliente é importante, pois detecta falhas, minimiza tempo e custo por retrabalho. Na fase de suporte do produto, o Usuário já teria bastante conhecimento sobre o produto e/ou seu funcionamento, servindo de apoio para outros clientes.

Atualmente, as possibilidades de o consumidor se comunicar com as empresas e com outros consumidores, no propósito conjunto de criar valor, são inúmeras. No entanto, pouco se sabe sobre os papéis que o consumidor desempenha no processo de cocriação no mercado brasileiro. Daí surge o segundo objetivo específico desta pesquisa: analisar os papéis desempenhados pelo consumidor no processo de cocriação de valor na internet.

\section{MÉTODO DA PESQUISA}

Para atingir os objetivos propostos, a Figura 3 traz o resumo do método desta pesquisa. Para identificar os ramos de atividade em que a pesquisa seria realizada estabeleceram-se dois critérios: 1) realizar atividade altamente afetada pelo avanço tecnológico; 2) possuir ofertas voltadas para o consumidor final. Surgiram como relevantes telefonia celular, eletroeletrônicos, alimentos e serviços bancários. Neste artigo são relatados os resultados do setor de telefonia celular no Brasil.

Para o primeiro objetivo específico optou-se pela análise de conteúdo dos websites das empresas do setor. Esse tipo de análise é definido por Bardin (2004, p. 37) como um conjunto de técnicas com procedimentos sistemáticos e objetivos, realizado por meio de indicadores qualitativos ou quantitativos. Para a coleta de dados utilizou-se uma relação das ferramentas de cocriação na internet elaborada a partir de Prandelli et al. (2006) e Nambisan \& Nambisan (2008). Redes sociais (como Del.icio.us, Digg, Facebook, Flickr, Google accounts, Linkedin, Live MSN, Myspace, Orkut, Twitter, Yahoo Bookmark e Youtube), que surgiram ou se popularizaram após esses estudos, foram incluídas

Revista de Administração e Inovação, São Paulo, v. 9, n.3, p. 257-272, jul/set. 2012. 
nessa relação. Isso porque elas constituem atualmente um dos símbolos mais fortes de conexão entre indivíduos e a forma de comunicação que mais cresce, sendo responsável por $62 \%$ do tráfego na internet (Neto, 2009). A análise dos websites seguiu os seguintes passos: 1) identificar a(s) ferramenta(s) disponíveis para interagir com o consumidor; explorar a(s) ferramenta(s) identificada(s) no $1^{\circ}$ passo, inferindo o(s) objetivo(s) da empresa. Os dados foram levantados em maio de 2011.

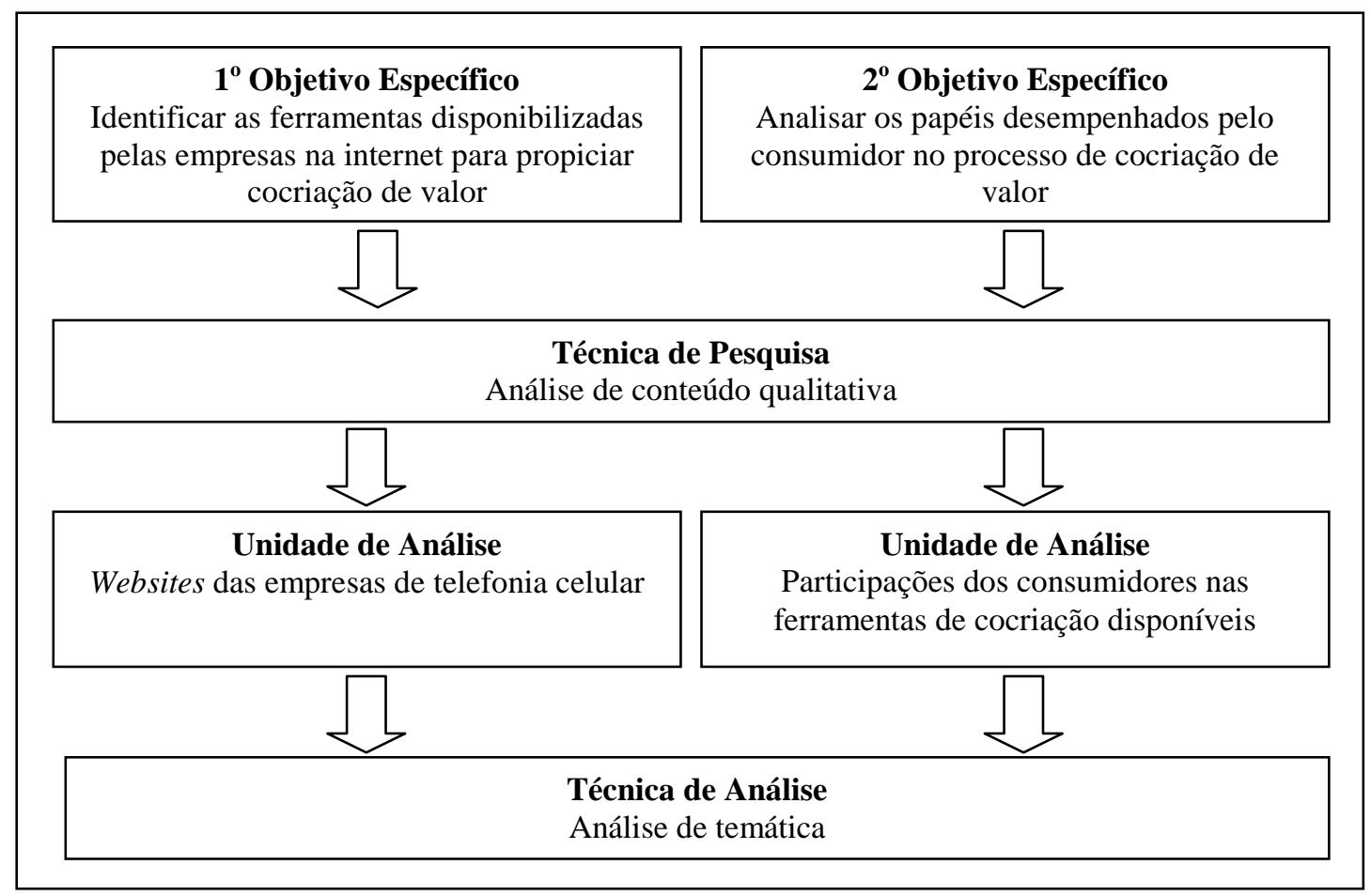

Figura 3 - Objetivos e Método da Pesquisa

Fonte: Elaborado pelos autores

Para o segundo objetivo específico foi feita análise de conteúdo qualitativa das participações dos consumidores nas ferramentas de cocriação na internet disponibilizadas pelas empresas. A construção das categorias de análise foi baseada nos conceitos de Nambisan (2002) sobre os papéis desempenhados pelo consumidor no processo de desenvolvimento de produtos. A análise foi feita buscando-se identificar as temáticas abordadas.

\subsection{Uso de ferramentas de cocriação na internet}

O uso de ferramentas de internet com o objetivo de cocriar é descrito a seguir para cada uma das empresas cujos websites foram analisados. No final da seção, a Figura 4 resume os achados.

Vivo - em seção restrita apenas para clientes, as áreas encontradas no website foram: i) programa de fidelidade com acumulação de pontos; ii) chat online para dúvidas sobre aparelhos; iii) 
agendamento de atendimento em loja. Em todas elas, o objetivo da empresa parece ser esclarecer dúvidas dos consumidores sobre os serviços disponíveis.

Quanto a Redes Sociais, a empresa utiliza Facebook, Twitter e RSS. A descrição do perfil da empresa no Facebook indica que o objetivo é convidar os consumidores para troca de ideias e interação, deixando as dúvidas sobre produtos e serviços para o canal de Atendimento, em loja e no Twitter.

A Vivo envia aos usuários cadastrados no Facebook notícias sobre lançamentos, aparelhos, atualizações de softwares, eventos, promoções etc. Em todas as redes sociais, a empresa informa o consumidor sobre ações de comunicação como promoções e eventos. Da rede social pode ser acessado o blog "Vivoon" e o "Vivo Blog Informação e Relacionamento". O primeiro é voltado para gerar conteúdo sobre artes, esportes, cultura, baladas, humor, variedades etc. O segundo está dividido em discussões sobre aplicativos, aparelhos, cultura, educação, games, inovação e sustentabilidade. Em cada tema do Vivo Blog a empresa posta notícias que podem ser comentadas pelos usuários. No geral, a impressão é que a empresa está interessada em levantar opiniões dos consumidores sobre produtos e serviços prestes a serem lançados ou que já estão disponíveis. Os blogs e o Facebook continham link para o YouTube apenas para acessar filmes das propagandas da empresa. As ferramentas utilizadas pela Vivo mostram que está focada nos dois últimos estágios do processo de desenvolvimento de produtos: lançamento e gerenciamento do ciclo de vida.

Claro - o website da empresa apresenta a possibilidade de atendimento online para tirar dúvidas, mas para isso é preciso fazer um cadastro e ser cliente da empresa. Há um ícone direto para o Facebook e um link para o Twitter do ex-jogador de futebol Ronaldo. Ele responde as mensagens que enviam, e a maioria delas é sobre futebol e sua nova carreira.

No website encontra-se o link para o Claro Blog, que estabelece como objetivo dar ao consumidor a oportunidade de opinar, discutir e compartilhar experiências. As áreas do blog são: Sobre o Blog, Código de Conduta, Vídeos, Podcasts, Nossos Blogueiros e RSS. Na página principal do blog encontram-se as postagens da empresa para propiciar a participação do consumidor. Elas são divididas em categorias: Dicas, Acontece, Por Dentro da Claro, Universo Móvel e Ideia Solta. Nessas categorias, a empresa posta conteúdo que os consumidores comentam. Na seção Ideia Solta, a empresa incentiva os consumidores a sugerir pautas, apontar melhorias para o blog, propor novos serviços ou produtos, recomendar eventos relacionados ao universo de telecomunicações, indicar vídeos interessantes, enfim propicia interação. Mas os temas são variados e pouco relacionados ao desenvolvimento de produtos. 
Diferentemente dos blogs da Vivo, o da Claro esclarece os termos de utilização e regulamenta a propriedade intelectual do que é postado. Todos os comentários dos usuários passam a ser propriedade da Claro. Portanto, há uma ferramenta ligada ao estágio de geração de ideias no processo de inovação.

Oi - no website da Oi as áreas encontradas foram: Programa de Fidelidade; Conhecer Produtos e Serviços; Resolver a Minha Vida Online, entre outros. Existem links para outros sites da empresa que propiciam interação: OI FM, Oi Futuro, Oi Acontece e Oi Moda. Todos estão relacionados, e um remete ao outro. O site Oi FM, além de links para Facebook, Twitter, Youtube e Flickr, apresenta um blog e uma aba especial "Interaja". Essa última, junto ao Oi Moda, são as únicas ferramentas que oferecem interação com o consumidor. As outras se restringem a fornecer informações sobre lazer e curiosidades. Na aba denominada "Interaja" há espaço para o consumidor influenciar a programação, deixar fotografias, recados para apresentadores, alertas sobre as músicas, jogar e participar de concursos. Também há uma seção especial para ensinar os ouvintes a interagir com a rádio usando diversos modelos de celular. OI Moda dá dicas e mostra novidades e looks sempre com espaço para comentários dos internautas.

As ferramentas utilizadas pela Oi estão relacionadas a aspectos de entretenimento. Não foram encontrados indícios de que a empresa esteja interessada em propiciar a participação do consumidor para desenvolver produtos. O consumidor é considerado Usuário, pois a empresa utiliza ferramentas como website, chat online e telefone para atendimento sobre produtos e serviços disponíveis.

Nextel - a página principal apresenta links para Twitter, Facebook e Youtube, estando todos interligados entre si. No Facebook, há convite para entrar em um website independente, especializado em envolver os usuários no processo criativo de comunicações de marketing: www.zooppa.com.br. Trata-se de uma empresa prestadora de serviços especializada em gerenciar contribuições de consumidores, levantadas por meio de concursos, para serem utilizadas por empresas na criação de campanhas de comunicação. Esse mecanismo é apontado como uma ferramenta para geração de ideias na literatura (ver Figura 1), no entanto, neste caso, ela é utilizada por uma empresa externa à analisada. O que a Nextel pretendia com a contratação desse serviço é que os usuários propusessem argumentos de venda que poderiam ser utilizados em sua comunicação. No geral, as ferramentas proporcionadas pela empresa estão voltadas para a avaliação dos produtos e serviços já oferecidos. Não há uso de instrumentos que incentivem os usuários a participar no desenvolvimento de produtos.

Tim - a página inicial do site da Tim indica um telefone do Fale com a Tim 1056, de Atendimento a Deficientes Auditivos, Twitter e Facebook. No Twitter, as mensagens enviadas pelos 
usuários não podem ser visualizadas. Só aparecem as respostas da empresa que são principalmente sobre dúvidas gerais em relação a produtos, promoções e funcionamento de aparelhos. A Tim também posta mensagens informando oportunidade de estágios, prorrogações de promoções, prêmios e concursos. No caso de informações pessoais sobre contas, o cliente é encaminhado para a Central de Atendimento. O website tem também um link direto para o Facebook, que só apresenta a história da empresa e a possibilidade de curtir ou não. Além disso, na página inicial do site, em "Eu Quero", temse a opção de Falar com a Tim por e-mail, carta, telefone e celular. As indicações são de que por esses meios é possível tirar dúvidas, criticar e elogiar. O site da empresa não apresenta opções diretas de participação do consumidor em processos de cocriação. $\mathrm{O}$ uso de redes sociais tem apenas função informativa sobre questões gerais da empresa. O consumidor é visto como Usuário.

Sercomtel - a página inicial do website da empresa apresenta os telefones do Serviço de Atendimento ao Consumidor (SAC) e da Ouvidoria para contato de clientes. No Fale Conosco, reservado para solução de dúvidas, críticas ou sugestões por e-mail, só se consegue acesso fazendo cadastro com um número de telefone e senha. A empresa tem Twitter, mas isso não estava especificado no site. Seu Twitter foi acessado pelo Google e, quando acessado, a instrução foi ligar para o telefone 1051 (SAC), pois a área estava em construção. A empresa também tem Facebook, encontrado através do Google, mas só apresenta o histórico, dizendo que é a única operadora de telefonia móvel pública do país, com sede em Londrina, Paraná. Essas duas ferramentas não apresentam nenhuma possibilidade de interação com o consumidor, mas como estão em processo de construção, talvez a empresa esteja planejando fomentar a participação dos usuários.

\begin{tabular}{|c|c|c|c|c|c|c|c|}
\hline \multirow[t]{2}{*}{ Empresa } & \multicolumn{7}{|c|}{ Objetivos das Ferramentas de Internet por Empresa } \\
\hline & Chat & Blog & Twitter & Facebook & RSS & Flickr & YouTube \\
\hline Vivo & $\begin{array}{l}\text { Responder } \\
\text { a dúvidas } \\
\text { sobre } \\
\text { aparelhos }\end{array}$ & $\begin{array}{l}\text { Informar sobre } \\
\text { lançamentos } \\
\text { de produtos e } \\
\text { serviços e } \\
\text { entretenimento }\end{array}$ & $\begin{array}{l}\text { Responder a } \\
\text { dúvidas sobre } \\
\text { produtos e } \\
\text { serviços }\end{array}$ & $\begin{array}{l}\text { Trocar ideias e } \\
\text { informações } \\
\text { sobre } \\
\text { aparelhos e } \\
\text { eventos }\end{array}$ & $\begin{array}{l}\text { Informar } \\
\text { sobre } \\
\text { atualizar o } \\
\text { website }\end{array}$ & --- & $\begin{array}{l}\text { Propagandas } \\
\text { da empresa }\end{array}$ \\
\hline Claro & $\begin{array}{l}\text { Dúvidas } \\
\text { sobre } \\
\text { contas }\end{array}$ & $\begin{array}{l}\text { Propiciar } \\
\text { participação } \\
\text { do consumidor } \\
\text { na cocriação }\end{array}$ & $\begin{array}{l}\text { Informar sobre } \\
\text { entretenimento }\end{array}$ & $\begin{array}{l}\text { Informar } \\
\text { promoções e } \\
\text { entretenimento }\end{array}$ & $\begin{array}{l}\text { Atualizaçõ } \\
\text { es sobre o } \\
\text { Blog }\end{array}$ & --- & --- \\
\hline Oi & $\begin{array}{l}\text { Informar } \\
\text { sobre } \\
\text { produtos e }\end{array}$ & --- & $\begin{array}{l}\text { Informar sobre } \\
\text { entretenimento }\end{array}$ & $\begin{array}{l}\text { Informar sobre } \\
\text { entretenimento }\end{array}$ & --- & $\begin{array}{l}\text { Informar sobre } \\
\text { entretenimento }\end{array}$ & $\begin{array}{l}\text { Conteúdo de } \\
\text { entretenimento }\end{array}$ \\
\hline
\end{tabular}

Revista de Administração e Inovação, São Paulo, v. 9, n.3, p. 257-272, jul/set. 2012. 


\begin{tabular}{|c|c|c|c|c|c|c|c|}
\hline & serviços & & & & & & \\
\hline Nextel & --- & --- & --- & $\begin{array}{l}\text { Informar e } \\
\text { responder } \\
\text { dúvidas sobre } \\
\text { produtos e } \\
\text { serviços }\end{array}$ & & & \\
\hline Tim & --- & --- & $\begin{array}{l}\text { Responder } \\
\text { dúvidas e } \\
\text { informar sobre } \\
\text { produtos, } \\
\text { serviços, } \\
\text { oportunidades } \\
\text { promoções e } \\
\text { concursos }\end{array}$ & $\begin{array}{l}\text { Informar sobre } \\
\text { a história da } \\
\text { empresa }\end{array}$ & --- & --- & --- \\
\hline
\end{tabular}

Figura 4 - Resumo dos Objetivos das Ferramentas de Internet por Empresa

Fonte: Elaborado pelos autores

\subsection{Papéis do consumidor no Processo de Desenvolvimento de Produtos}

Nesta seção é feita a análise do papel do consumidor no Processo de Desenvolvimento de Produtos. No final, a Figura 5 consolida os achados.

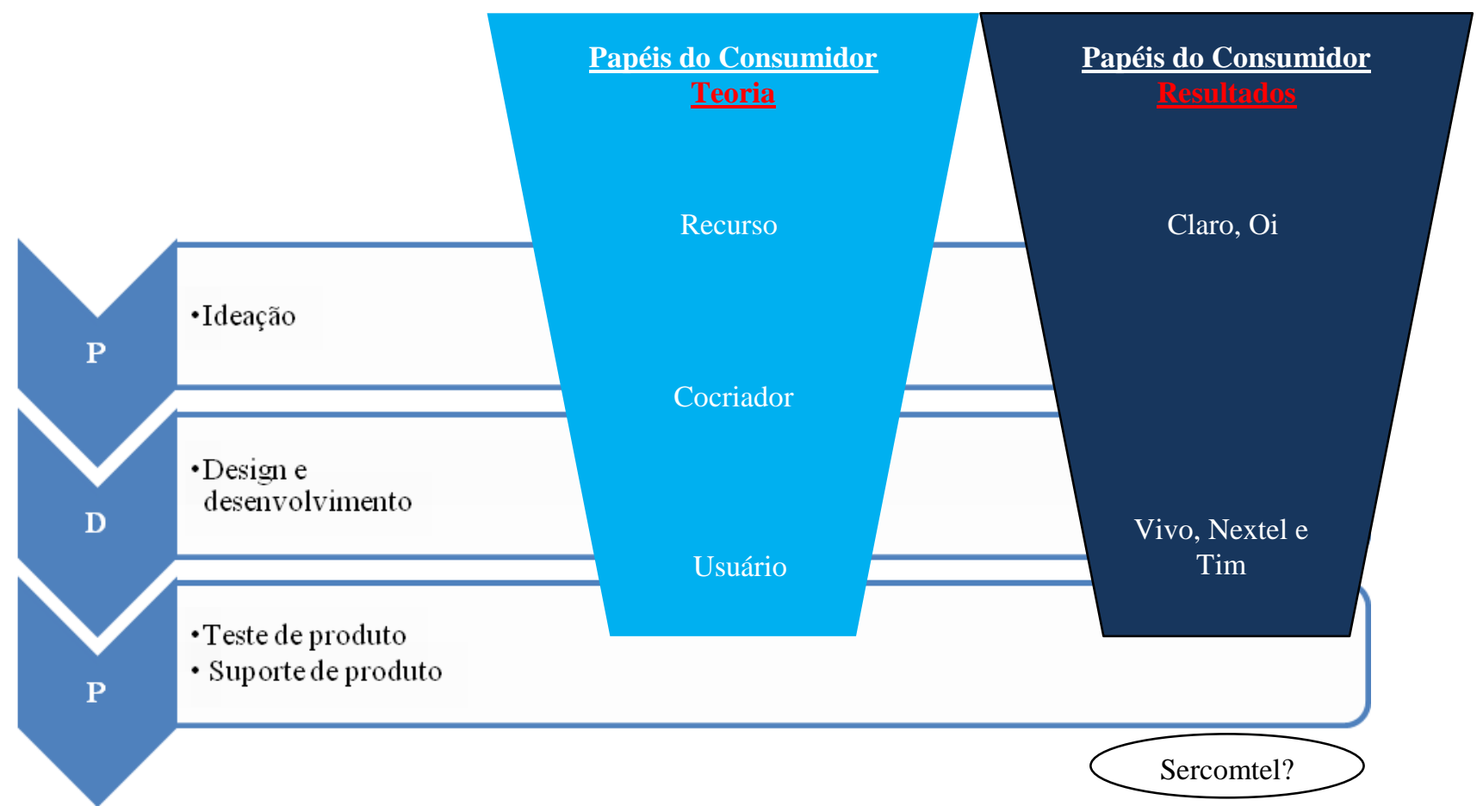

Figura 5 - Papéis do Consumidor no Processo de Desenvolvimento de Produtos: Teoria Versus Resultados

Fonte: Elaborado pelos autores

Revista de Administração e Inovação, São Paulo, v. 9, n.3, p. 257-272, jul/set. 2012. 
Na empresa Vivo foram analisados os comentários dos consumidores no Vivo Blog. Apesar do uso de redes sociais e blogs, observou-se que a participação do consumidor está restrita ao papel de Usuário. As discussões dos consumidores eram sobre serviços (características e preços) prestados pela operadora.

Na Claro, a área "Ideia Solta" no blog é usada de acordo com a proposta da empresa. A maioria dos consumidores posta sugestões de planos e serviços, além de melhorias no atendimento. Nesse caso, o consumidor desempenha papel de Recurso no estágio de geração de ideias do processo.

A participação do consumidor no site da OI não fica disponível no website. Aparentemente, as ferramentas para desenvolvimento de produtos são apropriadas somente pelo cliente no papel de Usuário, pois servem como suporte para as atividades em andamento e interação. As caixas de mensagens no site e no blog OI FM possibilitariam aos clientes participar como Cocriadores de ideias ou Recurso para a empresa. No entanto, apenas no Twitter ficam registradas as frases dos usuários, que, por serem restritas em termos de caracteres, impossibilitam avaliar a colaboração dos clientes.

$\mathrm{Na}$ Nextel, os visitantes do Facebook deixam seus comentários sobre modelos de aparelhos dos quais não gostaram e reclamações. A empresa tenta fazer com que o seu consumidor se envolva com a marca e suas comunidades, mas pelo conteúdo do site os internautas assumem o papel de Usuário, no qual todos os canais na internet servem como suporte para o produto.

$\mathrm{Na}$ Sercomtel, devido à indisponibilidade de ferramentas de cocriação, não houve dados para analisar a participação do consumidor.

Todas as possibilidades de comunicação dos consumidores da TIM com a empresa são feitas por meio de telefone ou e-mail e são restritas somente aos clientes. Não há acesso público a seus conteúdos. Fora isso, no Twitter, as mensagens enviadas pelos clientes são fechadas e só ficam disponíveis as respostas da empresa. Ao que tudo indica, os clientes participam apenas como Usuários.

Embora algumas empresas apresentem websites com mais estrutura para a cocriação de valor, aparentemente os clientes, em geral, não têm interesse ou pouco contribuem para desenvolver produtos.

\section{CONCLUSÕES}

O objetivo geral desta pesquisa foi estudar cocriação na internet, no Brasil. Os achados indicam que apesar dos websites das empresas estudadas utilizarem ferramentas de internet que possibilitariam a participação do consumidor, isso de fato não acontece. São poucos os consumidores que contribuem 
com o desenvolvimento de produtos. Estudo anterior, com análise de 200 websites de marcas e corporações, mostrou que as ferramentas de cocriação na internet não são sempre implementadas para acelerar e melhorar o desenvolvimento de produtos, por meio do envolvimento do consumidor (Prandelli et al., 2006). Apenas estágios específicos do processo eram contemplados com algumas ferramentas de comunicação, sendo que boa parte das empresas analisadas não as disponibilizavam. O mesmo pode ter acontecido nos websites aqui analisados, em que as ferramentas de internet objetivam levantar opiniões dos consumidores sobre produtos e serviços já ideados pela empresa. Ou seja, estrategicamente, as empresas focam mais os últimos estágios do processo de desenvolvimento de produtos (lançamento e gerenciamento do ciclo de vida de produto).

Os temas colocados pelas empresas nas redes sociais e nos blogs não estão propiciando cocriação de valor. Os comentários dos consumidores são sobre produtos e serviços criados internamente na empresa, servindo somente como validação daquilo que já está sendo comercializado. Talvez seja necessário que as empresas perguntem diretamente aos consumidores sobre possíveis novos produtos e serviços. Desse modo, eles passariam a ser um Recurso e talvez Cocriadores, deixando de ser apenas Usuários. A ligação entre as empresas e seus consumidores é fraca nas redes sociais, e é importante torná-la mais forte.

$\mathrm{Na}$ medida em que mais empresas evoluam na utilização de ferramentas de cocriação na internet, as fraquezas serão superadas e os pontos fortes, melhorados. No passado já se esperava que o contato com o consumidor por meio da internet se tornasse um paradigma para conseguir as informações requeridas pelas equipes de desenvolvimento de produtos. No entanto, isso ainda não é uma realidade. Inicialmente, as equipes de desenvolvimento de novos produtos terão de fazer escolhas. As velhas e novas formas de se comunicar com o consumidor coexistirão (Dahan \& Hauser, 2002). Acredita-se que se esteja em um processo de transição em que convivem a forma tradicional do processo de desenvolvimento de produtos e o uso de novas tecnologias para aprimorá-lo. Chamou a atenção o caso da Nextel, que terceiriza o levantamento de ideias do consumidor para a criação de campanhas de comunicação. Talvez esse seja um indicador de que a empresa se encontra em um estágio de transição. Utilizando ainda o modelo tradicional, a Nextel parece estar adquirindo expertise por meio de um prestador de serviços. Mas também é possível que esse seja o caminho a ser seguido pelas empresas do setor, deixando a gestão da participação do consumidor para empresas especializadas.

No propósito de viabilizar a participação do consumidor no processo de desenvolvimento de produtos na internet, algumas considerações são necessárias. De um lado, o entendimento da gestão e do impacto das novas relações que serão estabelecidas com os clientes exige a integração das perspectivas organizacionais e de marketing (Goodman et al., 1995). Isto é, as empresas devem ser 
estruturadas de forma a suportar as novas demandas exigidas pelo envolvimento do consumidor no processo de desenvolvimento de produtos. Por outro lado, as empresas devem não somente decidir as funções específicas que os clientes desempenharão na criação de valor, mas reconhecer e incorporar diferenças subjacentes entre os papéis (em termos de padrões de interação, de processos de criação de conhecimento, motivações etc.) desempenhados pelos consumidores nas diversas ferramentas de cocriação na internet (Nambisan, 2002).

Por fim, um aspecto crítico do projeto de envolver o consumidor inclui a identificação das estratégias que nortearão a criação de valor e a apropriação desse valor, conciliando as condições ou requisitos para cada um (Moran \& Ghoshal, 1999). Nesta pesquisa houve indícios de certa preocupação do consumidor a colaborar com a empresa, pois não estão claros os benefícios para ele. No caso da Claro, a empresa passa a ser "dona" de todas as ideias postadas pelos usuários. Nas concorrentes, esse assunto não é mencionado. Desta pesquisa surgem alguns direcionamentos para trabalhos futuros. Estudos sobre padrões de interação empresa-clientes, propriedade intelectual e motivações do consumidor para participar em processos de cocriação, entre outros, seriam recomendados. De forma mais específica, seria interessante investigar o papel da motivação intrínseca dos consumidores de se envolverem na geração de novas ideias ou se tornarem engajados o suficiente para assumir o papel de Recurso.

Do ponto de vista do desenvolvimento teórico, esta pesquisa contribui com conhecimento sobre um tema ainda pouco estudado no ambiente acadêmico de marketing no Brasil: cocriação. Já do ponto de vista gerencial, as descobertas podem auxiliar as empresas a viabilizar a participação do consumidor ao longo das diversas etapas do processo de desenvolvimento de produtos.

\section{REFERÊNCIAS}

BARDIN, L. (2004). Análise de conteúdo. Lisboa: Edições 70.

BROWN, S. L.\& EISENHARDT, K. (1995). Product development: Past research, present findings, and future directions. Academy of Management Review, 20, 343-378.

DAHAN, E. \& HAUSER, J. (2002). The virtual customer. Journal of Product Innovation Management, 19(5), 332-53.

GOODMAN, P. S. et al. (1995). Customer-firm relationships, involvement and customer satisfaction. Academy of Management Journal, 38, 1310-1324.

GRÖNROOS, C. (2006). Adopting a service logic for marketing. Marketing Theory, 6(3), 317-333

Revista de Administração e Inovação, São Paulo, v. 9, n.3, p. 257-272, jul/set. 2012. 
MATZLER, K. \& BAILOM, F. (2006). Top management innovation orientation, market orientation and competence management as antecedents of product innovation success and firm performance. In: International Product Development Management Conference, Milan.

MORAN, P. \& GHOSHAL, S. (1999). Markets, firms, and the process of economic development. Academy of Management Review, 24, 390-412.

NAMBISAN, S. (2002). Designing virtual customer environments for new product development: toward a theory. Academy of Management Review, 27(3), 392-413.

NAMBISAN, S.\& NAMBISAN, P. (2008). How to profit from a better "virtual customer environment". MitSloan Management Review, 49(3), 53-61.

NETO, G. (2009). Redes sociais são responsáveis por 62\% do tráfego na Internet brasileira. Disponível em: <http://www.mundodomarketing.com.br/10,11077, redes-sociais-são-responsaveis-por-62-dotrafego-na-internet-brasileira.htm>. Acesso em: 30 dez. 2009.

PALMER, D. (2007) Harnessing consumer inspiration in new product development: non- traditional for working with consumers at the "fuzzy front end". Innovation Point, 2007. Disponível em: http://www.innovation-point.com. Acesso em: 01 maio 2011.

PRAHALAD, C. K. \& RAMASWAMY, V. (2004) The Future of Competition: Co-Creating Value with Customers. Boston, MA: Harvard Business School Press.

PRAHALAD, C. K. \& RAMASWAMY, V. (2000). Co-opting customer competence, Harvard Business Review, 78(1), 79-87.

PRANDELLI, E. et al. (2006). Diffusion of Web-based product innovation. California Management Review, 48(4), 109-135.

SRINIVASAN et al. (2009). Product innovations, advertising, and stock returns. Journal of Marketing, 73(1), 24-43.

THOMKE, S. \& VON HIPPEL, E. (2002). Customers as Innovators: A New Way to Create Value. Harvard Business Review, 80(4), 74-81.

URDAN, A. T. \& URDAN, F. T. (2006). Gestão do composto de marketing. São Paulo: Atlas.

VARGO, S. L.\& LUSCH, R. F. (2004). Evolving to a New Dominant Logic for Marketing, Journal of Marketing, 68(1), 1-17.

WAYLAND, R. \& COLE, P. (1997). Customer connections. Boston: Harvard Business School Press. 


\title{
CO-CREATION IN INTERNET: AN ANALYSIS OF PERSPECTIVES OF COMPANY AND CONSUMERS
}

\begin{abstract}
The objective of this research was to study co-creation on the Internet in Brazil, from two perspectives: the companies, identifying tools available to propitiate consumer participation in co-creation processes and the consumers, analyzing roles portrayed by them in that process. Content Analysis of websites and consumers' posts was chosen as the research method. Results show limited use of tools and the portrayed role of the consumer only as a user. The findings may help companies to facilitate the participation of the consumer through the various stages of products and services development process. Other implications are to produce insights for greater effectiveness in the use of the Internet in order to create value for consumers.
\end{abstract}

Key Words: Co-creation; Internet; Consumer; New Products; Cellular Telecommunications.

Data do recebimento do artigo: 15/05/2012

Data do aceite de publicação: 02/09/2012

Revista de Administração e Inovação, São Paulo, v. 9, n.3, p. 257-272, jul/set. 2012. 